\title{
FATIGUE OF RAILWAY STEEL CLIPS
}

\author{
M.F.E. IBRAHIM* M.S.GABRA ** \\ *Dept. of Machine Design, **Dept.of Aeronautical Engineering. \\ Military Technical College, Cairo-EGYPT.
}

\section{ABSTRACT}

Steel clips made from modified $5160 \mathrm{H}$ spring steel are used to hold down railway rails to sleepers. The clip has shown fatigue failure, and the cracks are so aligned as to indicate mixed mode loading, i.e. torsion and tension; the latter due to bending.

Specimens has been tested for torsional and push-pull fatigue. Biaxtal fatigue theories are used to achieve design conclusions in order to avoid fatigue failure of the clip.

\section{INTRODUCTION}

In many applications the effect of biaxiality of load on cracked components must be investigated bacause many structures are usually subjected to biaxial or multiaxial stresses. Experiments on the fatigue strength under combined completely reversed bending and torsion were carried out by a limited number of researchers. As a criteria of this loading condition, Gough $|1|$ published the ellipse arc and the ellipse quadrant formulae. Later, ductility effects were specially incorporated in the ellipse correlation of Gough et al $|2|$ by including both torsional ( $t$ ) and bending (b) fatigue strengthes. The ellipse quadrant for ductile steels related to the torsional and bending stresses, $S_{t}$ and $s_{b}$ resp., in a combined bending and torsion test is given by:

$$
\left(S_{t / t}\right)^{2}+\left(S_{b / b}\right)^{2}=1
$$

* Dept. of Machine Design, ** Dept. of Aeronautical Engineering. Military Technical College, Calro-EGYPT. 
Whereas for low ductility cast metals the ellipse arc was recommerided as follows:

$$
\left(S_{t} / t\right)^{2}+\left(S_{b} / b\right)^{2}+(b / t-1)+\left(S_{b} / b\right)(2-b / t)=1
$$

Another approach to the problem has been attempted by Brown and Miller $|3|$, to relate the fatigue strength of components sutjected to combined stresses to various fallure criteria, e.g. Rankine, Tresca, von Mises, St Venant theories ... etc.

Brown $|4|$ suggested that a plot of the maximum shear strain amplitude against the tensile strain amplitude normal to the plane of maximum shear will illustrate the controlling processes in fatigue crack growth at each state of strain.

The two strains mentioned above are represented on Mohr's circle of strain by the highest point of the largest Mohr's circle, see Fig. 1.

The co-ordinates of this point may be derfived in terms of the principal strains such that:

$$
\frac{\gamma}{2}=\frac{\varepsilon_{1}-\varepsilon_{3}}{2}
$$

where $\gamma$ is the maximum engineering shear strain, and

$$
\varepsilon_{n}=\frac{\varepsilon_{1}+\varepsilon_{3}}{2}
$$

where $\varepsilon_{n}$ is the tensile strain on plane of maximum shear.

Hence constant life contours

can be represented on a graph of $\gamma / 2$ against $\varepsilon_{n}$ by the equation

$$
\frac{\varepsilon_{1}-\varepsilon_{2}}{2}=f\left\{\frac{\varepsilon_{1}+\varepsilon_{3}}{2}\right\}
$$

where $\varepsilon_{1} \geqslant \varepsilon_{2} \geqslant \varepsilon_{3}$

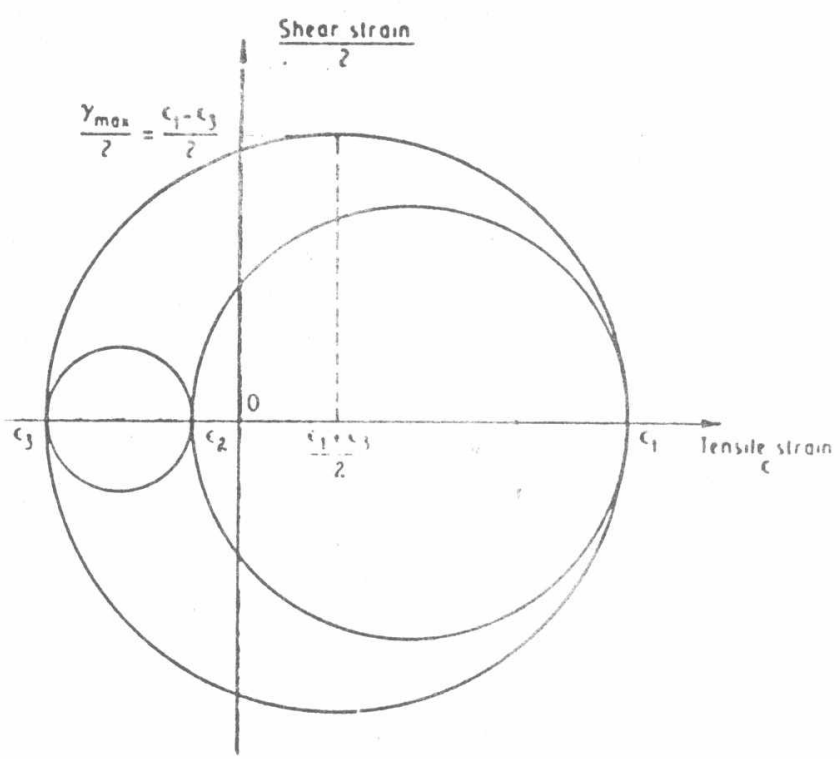

Fig. 1. Mohr's circle of strain 
Henceforward, the graph of maximum shear strain, $\gamma / 2$, against the tensile strain, $\varepsilon_{n}$, normal to the maximum shear strain plane is known as the $\Gamma-$ plane, and the contours of constant endurance are called as the $\Gamma$-plots. Thus each $\Gamma$-plot is associated with a given 1 ife.

In Fig. 2 graphs are plotted for Poisson's ratio of $\frac{1}{2}$ and $\frac{1}{3}$ in terms of $\varepsilon_{\mathrm{n}}$ and $\frac{1}{2} \Upsilon_{\max }$, on which four various failure criteria are represented by different 1oci, for a biaxial stress state.

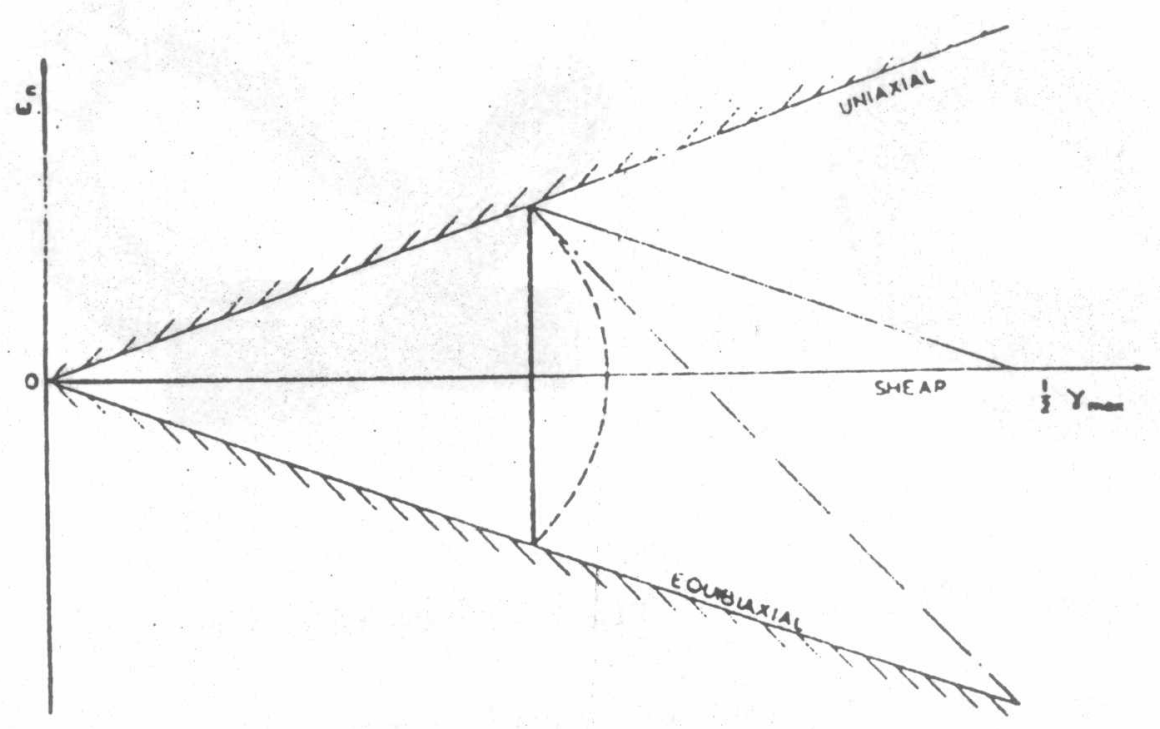

Key:

(a) For Poisson's ratio $=\frac{1}{2}$

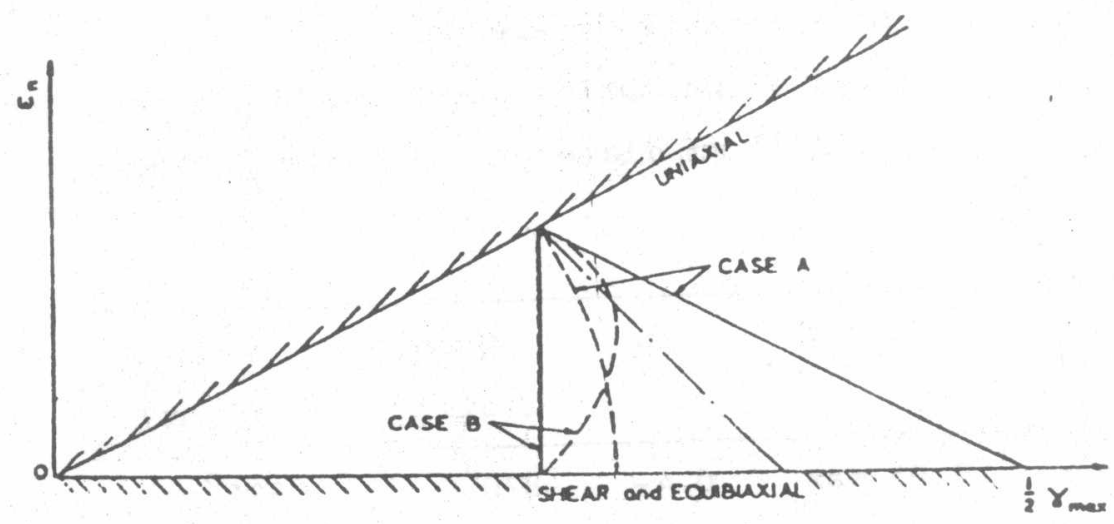

St Venant

(b) For Poisson's ratio $=\frac{1}{3}$

Fig.2. Classical Failure Critereria on the $\Gamma$-plane 


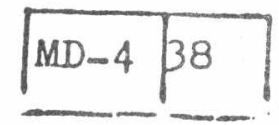

$\Gamma$
SECOND A.M.E. CONFIRENCE

6 - 8 May 1986 , Caro

\section{DESCRIBTION OF THE PROBLEM}

Figure 3 shows the stell clip that holds down rallway rails to sleepers. This clip has shown signs of fatigue, see Fig. 4. The cracks are so aligned as to indicate mixed mode loading, 1.e. torsion and tension the latter due to bending.
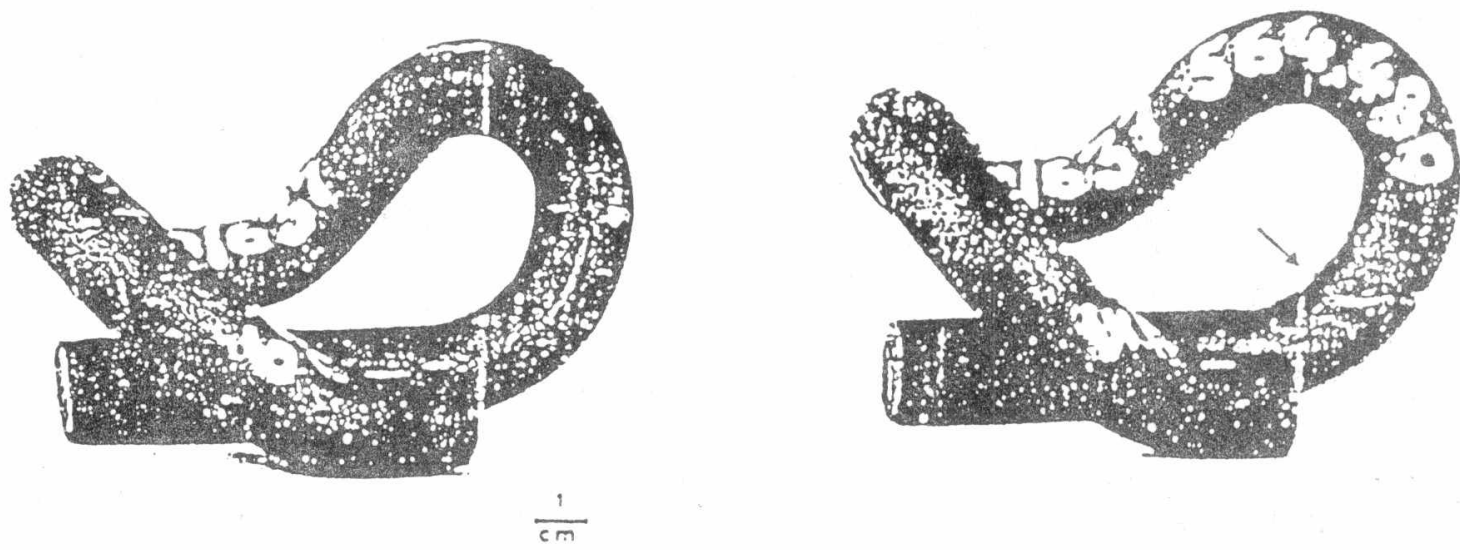

Fig. 3. The Steel Cl1p.

Fig.4. Fatigue Crack.

A preliminary examination of directions of loading suggested that the crack was initiated by shear loading due both torsional, and bending forces giving Stage I growth, and was then propagated in Stage II due to mainly untaxial loading, 1.e. Mode I crack development.

The material tested was a modified $5160 \mathrm{H}$ spring steel which was supplied in the form of hot pressed bars $22.25 \mathrm{~mm}$ diameter, with the. following composition and heat treatment.

\begin{tabular}{lllllll}
\hline $\mathrm{C}$ & $\mathrm{S}_{\mathrm{i}}$ & \multicolumn{1}{c}{$\mathrm{M}_{\mathrm{n}}$} & $\mathrm{P}+\mathrm{S}$ & $\mathrm{C}_{\mathrm{r}}$ & $\begin{array}{c}\text { Quen } \\
(011)\end{array}$ & $\begin{array}{l}\text { Temp. } \\
(1 \mathrm{hr})\end{array}$ \\
\hline $0.55-$ & $0.8-$ & $0.75-$ & $0.05 \max$ & $0.4-$ & $870^{\circ} \mathrm{C}$ & $525^{\circ} \mathrm{C}$ \\
0.65 & 1.1 & 1.0 & & 0.6 & & \\
\hline
\end{tabular}

The mechanical properties of this steel are as follows:

$0.2 \%$ proof stress

Ultimate tensile strength

Percentage elongation

$=1277.24 \quad \mathrm{MP}_{\mathrm{a}}$

$=1408.52 \quad \mathrm{MPa}$

$=11$ 
\begin{tabular}{l|l}
$M$ & 39
\end{tabular}

Percentage reduction in area

Impac $t$

Grain size
SECOND A.M.E. CONFIRENCE

6 - 8 May 1986 , Cairo

\section{EXPERIMENTAL STUDY}

Figure 5 shows the detailed dimensions of the fatigue test specimen cut from the $22.25 \mathrm{~mm}$ bars. The specimens were finished by polishing alternatively in longitudinal, helical and circumferential directions with successively finer grades of emery paper, the final polishing being done with grade 4/0 paper circumfrentially. They were then carefully inspected under a microscope to ensure that no serious scratches remained. Random measurement of surface roughness of three specimens showed that the maximum CLA was $0.1 \mu \mathrm{m}$.

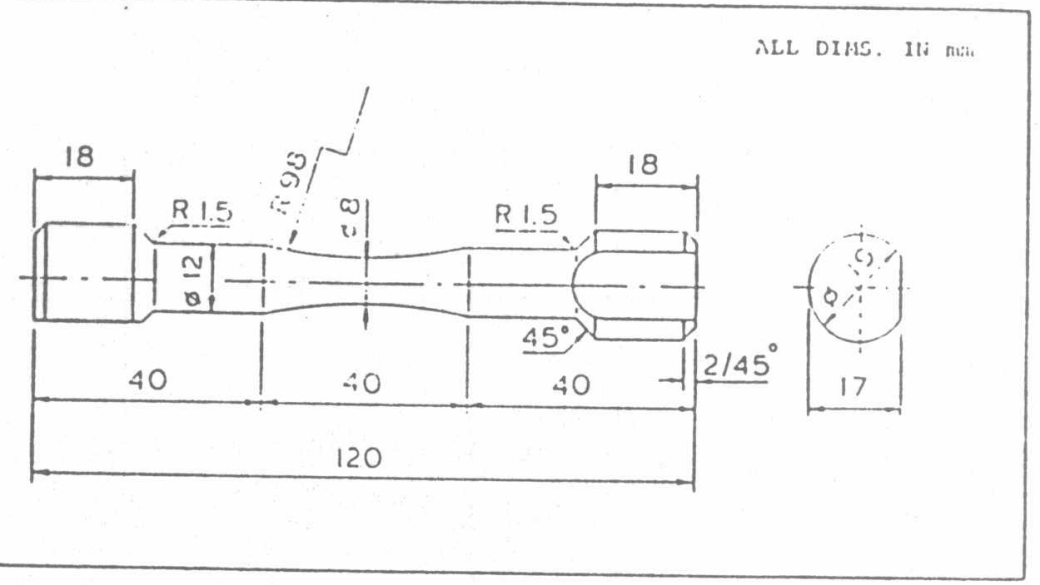

Fig.5. Specimen Geometry.

\section{Torsion Fatigue Test:}

The torsion fatigue peoperties were produced from the testing of 10 specimens. Cyclic torsion was carried out under constant strain limits controlled by the applied angle of twist $\Delta \theta$.

A record of torque against angle of twist obtained from a mutiple step test at different strain levels produced on one specimen is shown in Fig. 6. The cyclic stress-strain curve, shown in Fig. 7. was also derived for the $5160 \mathrm{H}$ spring steel specimens. 


\section{$M D - 4 \longdiv { 4 0 }$}

$\Gamma$
SECOND A.M.E. CONFERENCE

6 - 8 May 1986 , Cairo

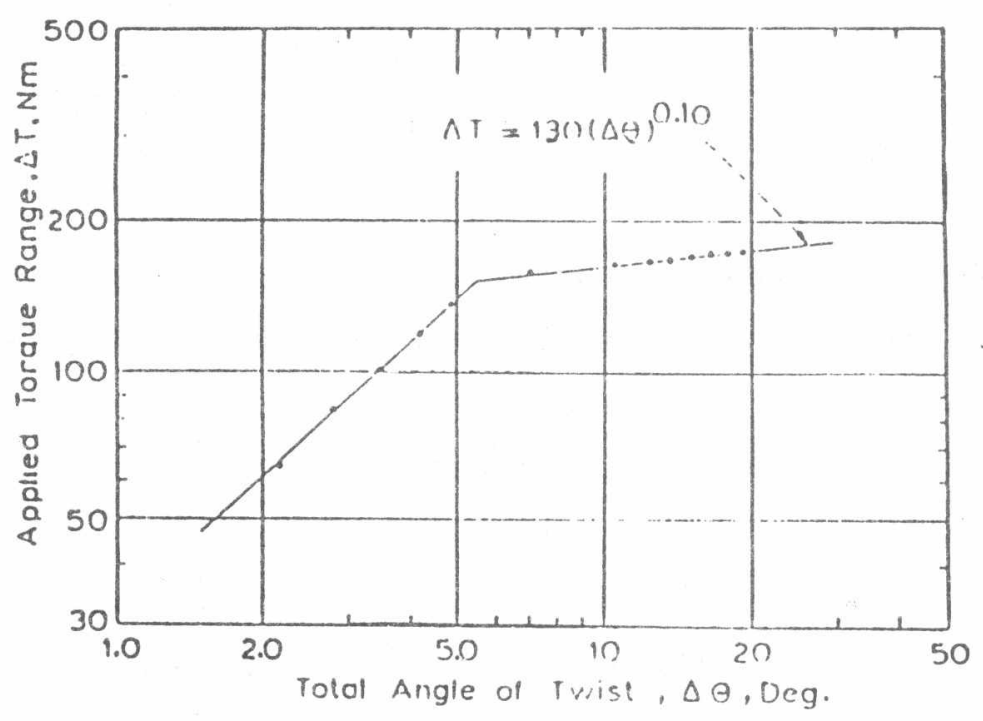

Fig.6. To $r$ que vs Twist characteristic.

F1g.7. Shear stress vs shearstrain characteristic.

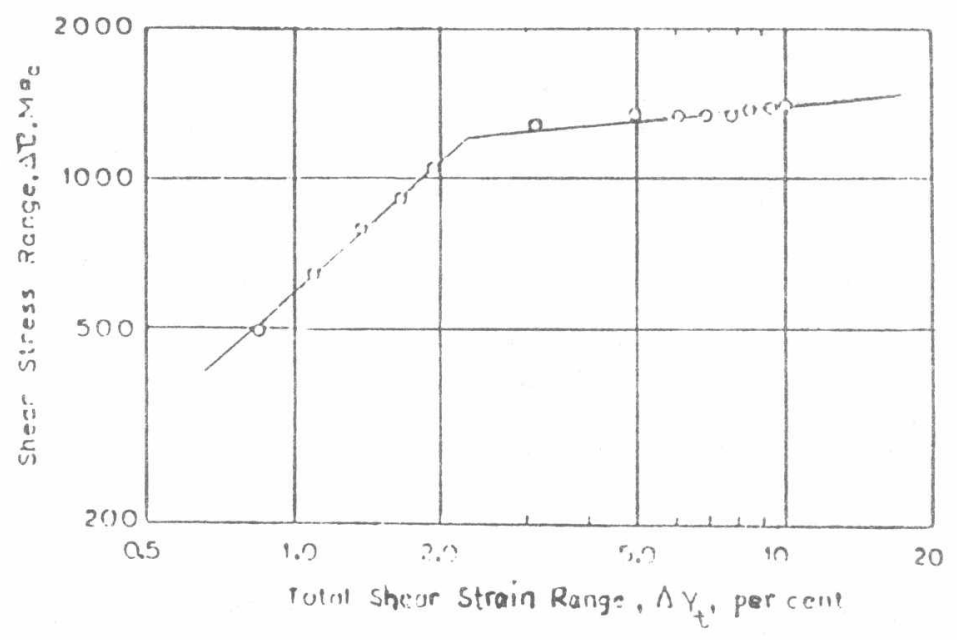

The fatigue test results are tabulated in Table $I$, and plotted in Fig.8. The $\Delta t$ vs $N_{f}$ curve does not exhibit a clearly discrenable break within the performed range of tests. Considering the fatigue strength corresponding to 10 million cycles as a convenient base for design, the fatigue strength may be taken as equal to $\pm 300 \mathrm{MPa}$. 
Table I. Torsion Fatlgue Test

\begin{tabular}{|c|c|c|c|c|c|c|}
\hline $\begin{array}{c}\text { Spec. } \\
\text { pto. }\end{array}$ & $\begin{array}{c}\text { Mln. } \\
\text { Dlam. } \\
\text { d }\end{array}$ & $\begin{array}{c}\text { Total Angle } \\
\text { of Twist } \\
\Delta \theta\end{array}$ & $\begin{array}{c}\text { Applied } \\
\text { Torque } \\
\Delta \mathrm{T}\end{array}$ & $\begin{array}{c}\text { Shear } \\
\text { Stress } \\
\Delta T\end{array}$ & $\begin{array}{c}\text { shear } \\
\text { strain } \\
\Delta y_{t}\end{array}$ & $\begin{array}{c}\text { No. of. Cycles } \\
\text { to Fallure } \\
\mathrm{N}_{\mathrm{f}}\end{array}$ \\
\hline & $\mathrm{mm}$ & Deg. & $\mathrm{Nm}$ & $\mathrm{MPa}$ & P. & rycles \\
\hline 1 & 8.040 & 13.90 & 165.18 & $1262: 22$ & 7.09 & 160 \\
\hline 2 & 7.980 & 9.26 & 158.14 & 1235.91 & 1.13 & 590 \\
\hline 3 & 7.925 & 7.66 & 142.94 & 1140.49 & 3.51 & 920 \\
\hline 4 & 8.040 & 5.40 & 134.17 & 1025.27 & 2.26 & 4952 \\
\hline 5 & 8.020 & 3.80 & 111.81 & 860.80 & 1.51 & 33809 \\
\hline 6 & 7.890 & 3.50 & 100.63 & 797.15 & 1.39 & 75021 \\
\hline 7 & 8.040 & 3.20 & 96.90 & 725.16 & 1.27 & 221353 \\
\hline 8 & 8.030 & $3 . \infty$ & 92.43 & 694.57 & 1.19 & 768721 \\
\hline 9 & 8.030 & 2.80 & 85.72 & 614.16 & 1.11 & 357.32 .75 \\
\hline 10 & 7.890 & 2.20 & 67.83 & 518.46 & 0.88 & $1.65 \times: 0^{7}$ \\
\hline
\end{tabular}

- Unbroken

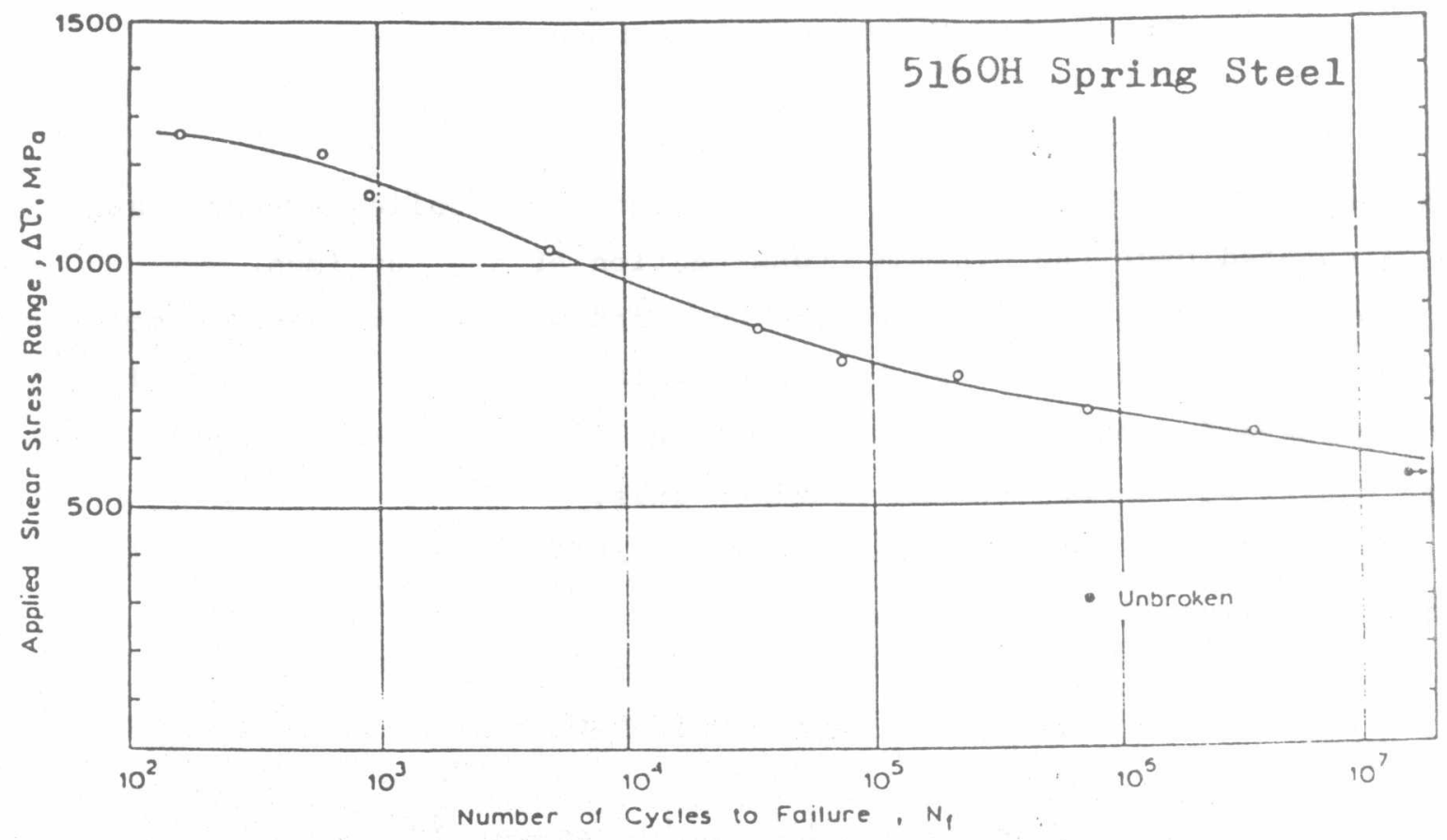

Fig.8 . Torsional Fatigue Endurance Behaviour.

\section{Push-Pull Fatigue Test:}

Another 10 specimens with the same geometry were fatigue tested under push-pull cycling with zero mean stress. The test was carried under stress control conditions. It was difficult to record the corresponding strain values because the transducer failed to clip on the extremely hard test specimen. However, the stress-strain cyclic behaviour was calculated 


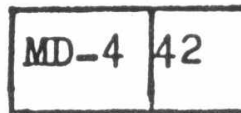

$\Gamma$

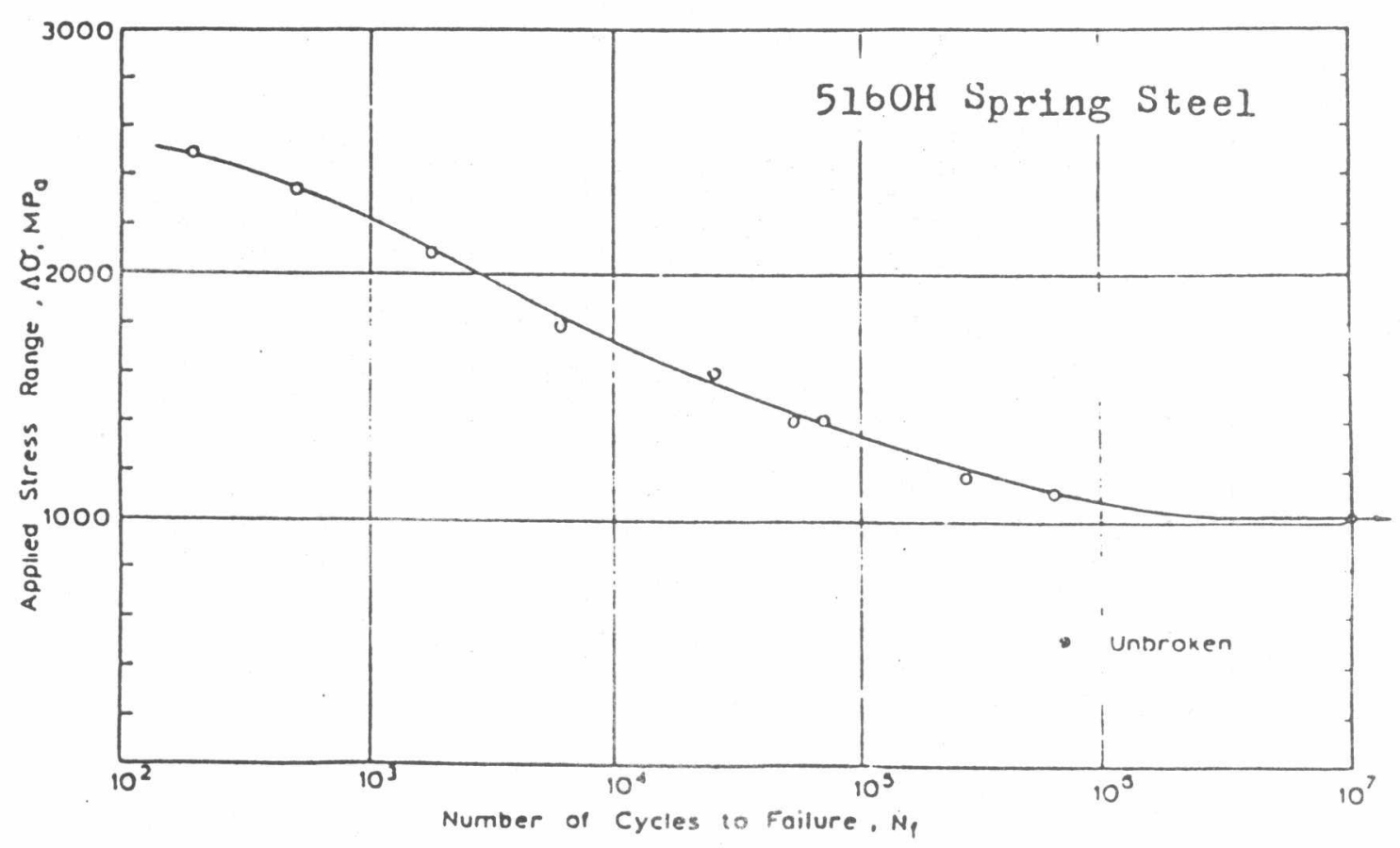

Fig.9. Push-Pul1 Fatigue Endurance Behaviour.

from that obtalned in torsion, Fig. $7|5|$. The applied stress range was calculated over the mintmum cross-section of the specimen.

The number of cycles to fallure were recorded when the specimen completly fractured. Observation of the fracture surfaces revealed that the slow crack propagation stage was typically Stage II whereas the unstable growth stage was at 45 degrees to the specimen axis.

The fatigue test results are tabulated in Table II and plotted in Fig.9, giving a fatigue $11 \mathrm{mit}$ at $\pm 510 \mathrm{MPa}$.

Table II Push-Pull Fatigue Test

\begin{tabular}{|c|c|c|c|c|}
\hline $\begin{array}{c}\text { Spec. } \\
\text { No. }\end{array}$ & $\begin{array}{l}\text { MIn. } \\
\text { diam. }\end{array}$ & $\begin{array}{l}\text { Ap } \\
\text { Lopdicd }\end{array}$ & $\begin{array}{c}\text { St.rias: } \\
\text { Range } \\
\text { An }\end{array}$ & $\begin{array}{c}\text { Ho. of rycles } \\
\text { to Fallure } \\
\mathrm{N}_{l}\end{array}$ \\
\hline & $\mathrm{mm}$ & $K N$ & MPO & \\
\hline 1 & 7.820 & 119.8 & 2194.33 & 191 \\
\hline 2 & 7.820 & 112.0 & 2331.93 & 502 \\
\hline 3 & 7.810 & 100.0 & 2087.41 & 1819 \\
\hline 4 & 7.920 & 80.0 & 1706.25 & 6143 \\
\hline 5 & 7.970 & 80.0 & 1600.00 & 25327 \\
\hline 6 & 7.930 & 69.7 & 1111.23 & 53.140 \\
\hline 7 & 7.910 & 70.0 & 1913.73 & 60368 \\
\hline 8 & 7.915 & 50.0 & 1178.79 & 275156 \\
\hline 9 & 7.070 & 51.3 & 1116.25 & (ינינה \\
\hline 10 & 7.950 & 50.5 & 1017.31 & $10^{7}$ \\
\hline
\end{tabular}


\begin{tabular}{|l|l|}
\hline$M D$ & 43 \\
\hline
\end{tabular}

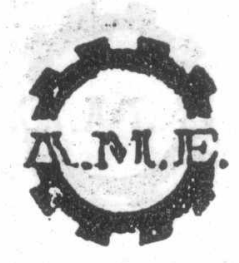

SECOND A.M.E. CONFERENCE

6 - 8 May 1986 , Cairo

$\Gamma$

BIAXIAL FATIGUE LIMIT PREDICTION

In order to predict the fatigue 1 imit under combined bending and torsIonal stress the "Gough" ellipse quadrant is suggested which is described by equation (1) .

The experimental data obtained under push-pull and torsion cyclic loading indicate via Figures 8 and 9 that

(i) the uniaxial fatigue strength

$\mathrm{b}= \pm 510 \mathrm{MPa}$.

(ii) the torsional fatigue strength

$t= \pm 300 \mathrm{MPa}$.

Substituting th ese values in equation (1) gives the predicted fatigue strength under biaxial loading situations, Point A, Fig. 10.'

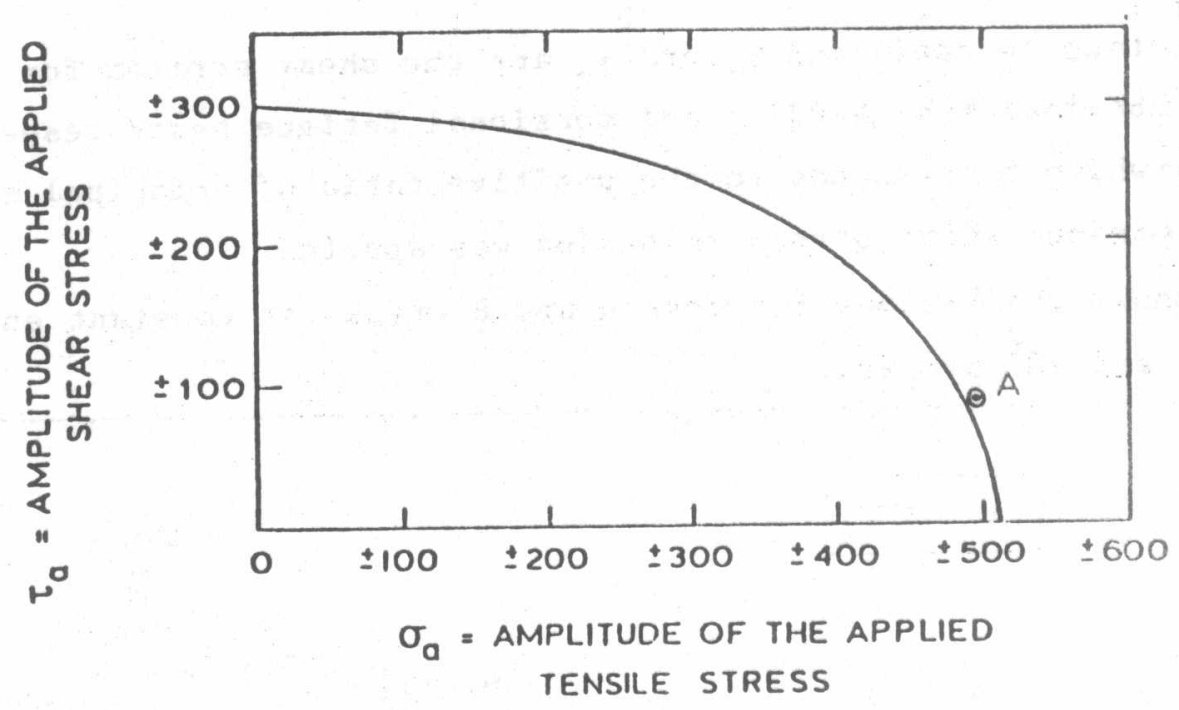

Fig.10. Gouph Ellipse Quadrant for Biaxial Fatigue limit Prediction. 


\section{CONTOURS OF CONSTANT ENDURANCE}

Fatigue life is controlled by the maximum shear strain, $Y$ max' and the normal strain on that plane of maximum shear $\varepsilon_{n}$, or slimply.

$$
N_{f}=f\left(r_{\max }, \varepsilon_{n}\right)
$$

Two types of fatigue cracks, labelled as cases $A$ and $B|6|$, may result corresponding to the orientation of the free surface with respect to the axes of principal strain. Contours of constant endurance for case $A$ and case $B$ fatigue cracks are usually presented on a graph of $\frac{1}{2} \gamma$ max vs $\varepsilon_{n}$, which is termed a $\Gamma$-plane.

For the derivation of the formulae representing the contours of constant endurance for case A cracks equation (1) was converted into strain terms to give the following format:

$$
\left(\frac{r_{\max }}{r_{t}}\right)^{2}+4\left(\frac{1+v}{1-v}\right)^{2}\left(\frac{1}{\gamma_{b}^{2}}-\frac{1}{r_{l}^{\prime}}\right) \varepsilon_{n}^{2}=1
$$

where $\nu$ is polsson's ratio and $\gamma_{b}$ and $\gamma_{t}$ are the shear strains for a given life obtalned $f$ rom bending and torsional fatigue tests respectively. For case $B$, which corresponds to the positive ratio of principal stresses $\sigma_{2} / \sigma_{1}$, the maximum shear stress criterion was applied.

Figure 11 shows the $\Gamma$-plane for case A and B cracks at constant endurances of $10^{4}, 10^{5}$ and $10^{6}$ cycles.

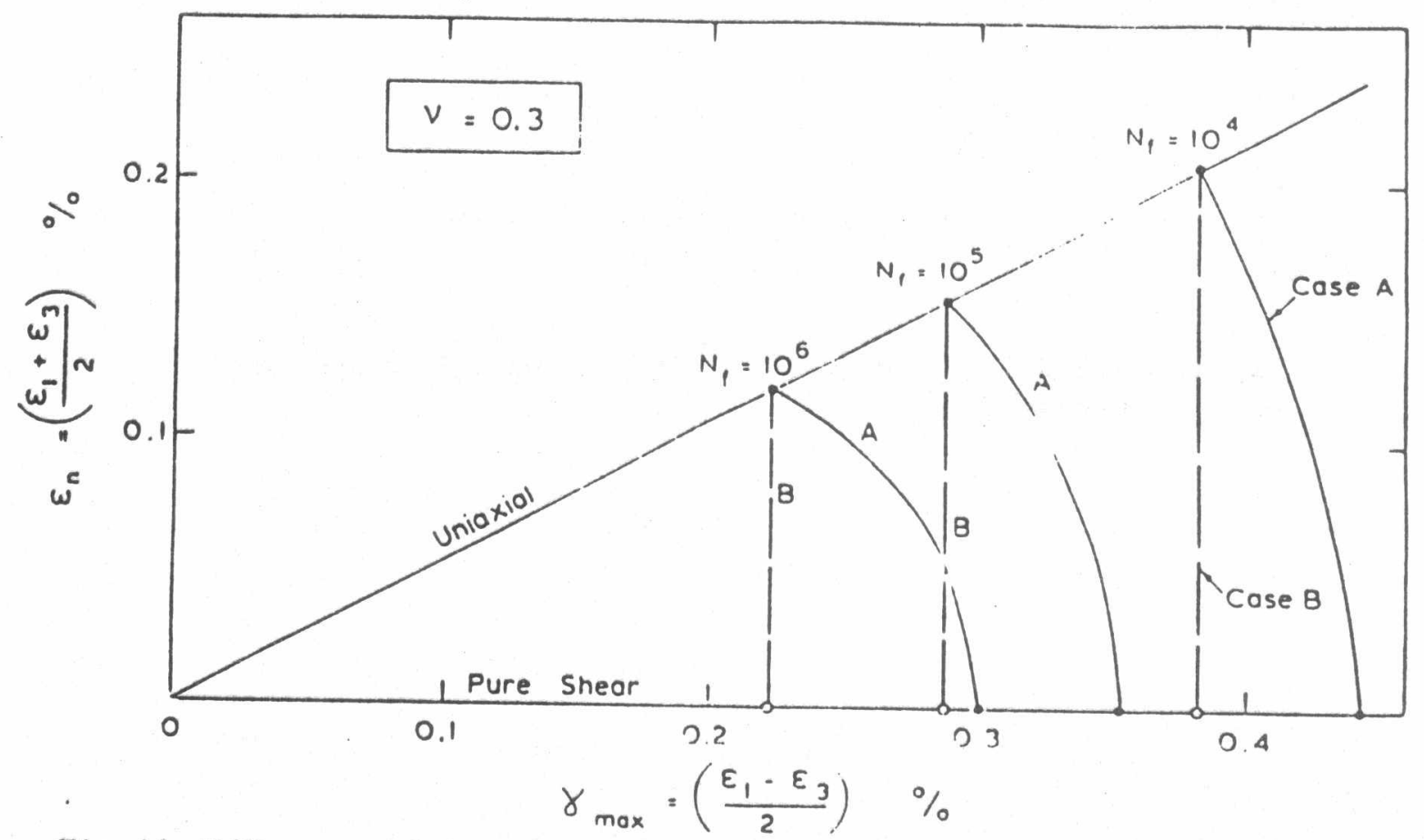

Fig.11. I-P1ane and Fatigue Life Contours for Biaxial Fatique Behaviour 
1. A Gough quadrant equation has been derived for the steel clip, subjectd to combined bending and torsion that induce spplied tensile and shear stresses, namely for an endurance of $10^{7} \mathrm{colles}$.

2. From the orientation of the crack ( $10^{\circ}$ from the transverse plane of the bar) it can be assumed from Mohr's circle of stress that the values of $\sigma_{\mathrm{a}}$ and $\tau_{\mathrm{a}}$ are $496 \mathrm{MPa}$ and $89 \mathrm{MPa}$, respectively, (see Fig. 12). When comparing this result with "Gough" ellipse, as indicated by point A in Fig. 10, shows that Gough predictions for failure under biaxial loading is safer.

3. In order to reduce the possibility of fatigue the maximum principal stress should be reduced, critical crack size increased and the surface finish improved.

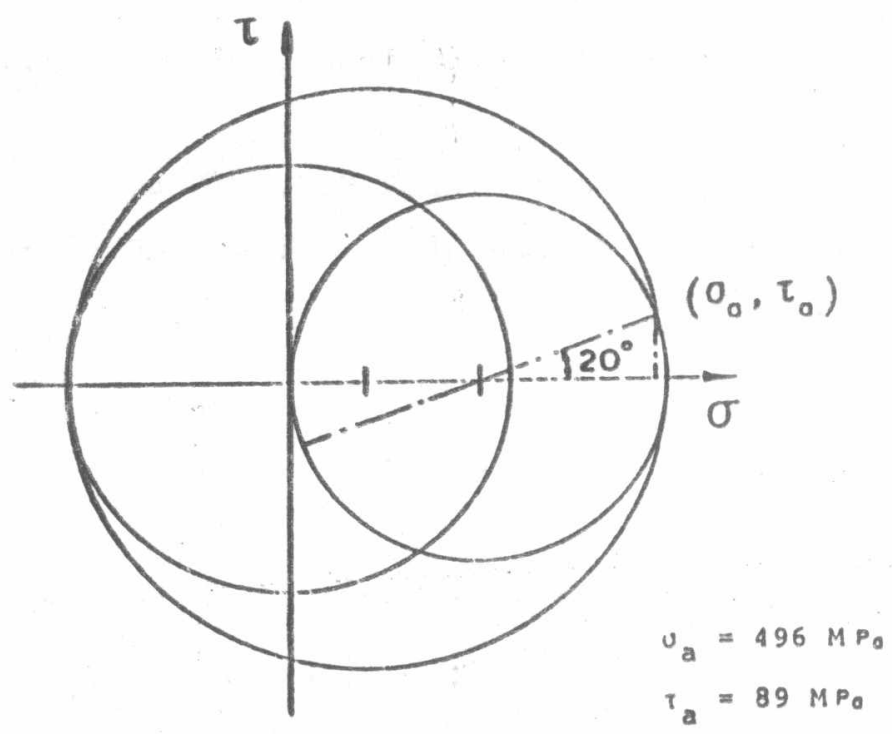

F18.12. Mohr's Stress Circle.

ACKNOWLEDGEMENT

The Authors are very grateful to Prof. K.J. Miller, Head of the Mechanical Eagtneertas Department, Sheffleld University for his encouragement and valuble suggestens. Thanks to Pandrol Claylands Forge for supply of the steel. 


\section{REFERENCES}

|1| GOUGH, H.J. and POLLARD, H.V., 1935 ,

'The strength of metals under combined alternating stresses; proc.

Instn :. Me ch. Engrs. Vol. 131.

|2| GOUGH, H.J., POLLARD, H.V. and

CLENSHAW, W.J., 1951, "Some experiments on the resistance of metals to fatigue under combined stress', Aero. Res Council Rep. Memo 2522.

|3| BROWN, M.W. and MILLER, K.J., 1973,

- A theory for fatigue fallure under multiaxial stress-stratn conditions', Proc. Instn. Mech. Engrs. Vol. 187.

|4| BROWN, M.W. and MILLER, K.J., 1979, 'Initlation and Growth of cracks in biaxlal fatigue', Fatigue Engng. Mat. Struct . Vol. 1.

|5| IBRAHIM, M.F.E., 1981,

- Early damage accumulation in metal fatigue', Ph. D. Thesis. Sheffield University.

|6| IBRAHIM, M.F.E, HAMMOUA, M.M.I. and MILLER, K.J., 1984,

'Mixed mode cumulative fatigue damage' Proc. First AME confr. MTC CAIRO, Vo1. 1 